$\mathcal{B} \mathcal{T} \mathcal{P} \mathcal{S}$

Brazilian Transportation Planning Society
Journal of Transport Literature

Vol. 6, n. 4, pp. 190-214, Oct 2012

Reviews \& Essays
JTL | RELIT

www.transport-literature.org ISSN 2238-1031

\title{
O desafio logístico na implantação de um aeroporto indústria no Brasil
}

[The logistics challenge in an industrial-airport implantation]

\author{
Roberta de Roode Torres Matera*
}

Universidade Federal do Rio de Janeiro (UFRJ), Brazil

Submitted 28 Aug 2011; received in revised form 12 Dec 2011; accepted 26 Jan 2012

\begin{abstract}
Resumo
À medida que a relação comercial entre os países aumenta, existe a necessidade que os órgãos governamentais incentivem as indústrias nacionais a procurar novos caminhos, para que elas possam se inserir com maior competitividade no mercado externo, trazendo assim um maior equilíbrio à balança comercial e ao crescimento do país. Para se atingir um sistema de distribuição mais barato e potencialmente mais estável, o sistema logístico inteiro deve ser eficiente. 0 conceito de AeroportoIndústria consolida esta necessidade de se intensificar a transformação dos sistemas de transporte e logísticos do país, proporcionando a instalação de plantas industriais em aeroportos internacionais com vista à exportação, com desburocratização, simplificação de procedimentos e redução de custos tarifários, tributários e logísticos, aumentando a competitividade das indústrias do país no mercado internacional. Com base neste contexto, este trabalho pretende mostrar a relação de dependência da cadeia logística eficiente no amparo à implantação de um Projeto Aeroporto-Indústria.
\end{abstract}

Palavras-Chave: aeroportos; logística; carga aérea; intermodalidade; economia.

\begin{abstract}
While the trade relationship among the countries increases, there is a necessity from the states to motivate its national industries to be inserted in a more competitive global market, providing then, equilibrium to its commercial balance and its development. To achieve a cheaper distribution system and potentially stable, the whole logistics system must be efficient. In short, this new set of logistical processes requires a logistical environment that is time-based, collaborative and flexible. The Industrial-Airport concept consolidates this necessity for the intensification of the logistic system of the Country, providing the installation of industrial plants in international airports specified for exportation with disbureaucracy, simplification of procedures and reduction of duties, taxes and logistics costs, increasing, on the other hand, the industrial competitiveness in an international global market. For this reason, this work intends to show the dependent relationship of an efficient logistic chain in the implementation of an Industrial-Airport.
\end{abstract}

Key words: airports; logistic; air cargo; intermodality; economy.

* Corresponding Author. Email: bel.matera@gmail.com.

\section{Recommended Citation}

Matera, R. R. T. (2012) 0 desafio logístico na implantação de um aeroporto indústria no Brasil. Journal of Transport Literature, vol. 6, n. 4, pp. 190-214.

- JTL/RELIT is a fully electronic, peer-reviewed, open access, international journal focused on emerging transport markets and published by BPTS - Brazilian Transport Planning Society. Website www.transport-literature.org. ISSN 2238-1031.

This paper is downloadable at www.transport-literature.org/open-access. 


\section{Introdução}

Com a crescente competição e a rápida evolução dos mercados, alterações substanciais estão ocorrendo na forma de conduzir negócios, ao redor do mundo. A mais marcante delas é a emergência de um novo cenário econômico, onde preço e qualidade são importantes, mas não mais suficientes para o sucesso comercial. Uma cadeia de suprimentos adequada, rapidez de atendimento ao mercado e agilidade em responder à demanda vêm, de forma crescente, assumindo papel essencial nas estratégias empresariais.

Seguindo a tendência governamental de incentivar o desenvolvimento do Comércio Exterior Brasileiro, o projeto "Aeroporto Industrial" consolida a necessidade de intensificar a transformação dos sistemas de transporte e logístico do país, proporcionando a instalação de plantas industriais em aeroportos internacionais/ internacionalizáveis com vistas à exportação, com desburocratização, simplificação de procedimentos e redução de custos tarifários, tributários e logísticos, aumentando a competitividade no mercado internacional.

Para atingir esse objetivo, este trabalho analisa, em suas duas primeiras seções, os dois grandes elementos de formação de um aeroporto-indústria, sendo o primeiro a carga aérea e o segundo a logística. Em seguida é apresentado o conceito e contexto de um Aeroportoindústria para, na seção 5 serem analisados os desafios de sua implantação no caso brasileiro.

Assim, a Seção 6 identifica restrições, barreiras e gargalos que dificultam a existência de uma adequada cadeia logística que visa em sua nova filosofia, uma estratégia competitiva, inferindo ao final sobre a estreita relação de dependência desta cadeia logística com a implantação do conceito de Aeroporto-Indústria à realidade brasileira.

\section{A carga aérea}

O transporte de carga aérea apresenta-se como uma modalidade de transporte de características bem específicas, por se destinar a atender, principalmente, mercados, sensíveis em relação ao tempo e segurança das entregas, à sazonalidade de seus produtos e mercados 
que apresentem problemas em relação à acessibilidade, seja pelas condições da infraestrutura de transporte ou pela distância ou ainda produtos de alto valor específico (Pedrinha, 2000).

Como nosso foco é a logística internacional, a avaliação acerca da natureza da carga torna-se fundamental. Nessa avaliação, devem ser apuradas questões como perecibilidade, fragilidade, periculosidade, dimensões e pesos considerados especiais. Entre os principais produtos cativos deste modal, destacam-se: (i) perecíveis como frutas, flores, peixes, jornais, revistas, artigos de moda; (ii) produtos de alto valor específico, como eletroeletrônicos, informática, jóias, ouro, etc e (iii) produtos com urgência de entrega como, remédios e peças de reposição.

O comércio aéreo vem criando novas indústrias, tais como artigos de moda e flores frescas para mercados distantes que, em poucas horas, agregam considerável valor aos produtos. Os clientes pagam não somente por produtos frescos ou perecíveis, mas pagam também pela satisfação extra da velocidade e confiabilidade na entrega de bens mais duráveis.

\subsection{Divisão Modal}

Tendo-se na abordagem dos planos e programas elaborados pelo Governo, o desafio da inserção do Brasil no contexto da globalização de mercados, pode-se afirmar que os transportes constituem-se em um dos setores prioritários para o desenvolvimento do país. No entanto, este setor foi norteado por uma política de investimentos concentrados no rodoviário, o que nos leva a questionar a sua adequação, consideradas as dimensões do território nacional.

A infraestrutura de transporte no Brasil, ainda insuficiente frente às dimensões do país e à produção nacional, e a baixa integração entre suas várias modalidades, vêm influenciando os altos custos do transporte brasileiro, hoje considerados como parte do Custo Brasil, e chegam a ultrapassar $200 \%$ os custos médios com transportes de países desenvolvidos, contribuindo, em grande parte, para o desequilíbrio verificado na matriz de transportes brasileira.

A modalidade aérea de transportes de carga ainda contribui com uma parcela insignificante do mercado de carga mundial, muitas vezes, por este motivo, sendo pouco abordada em vários estudos; suas taxas de crescimento, no entanto, apresentam saltos de crescimento em contraste a saltos de queda, oscilando conforme as flutuações da economia, como pode ser observado na tabela 2.1. 
Tabela 2.1: Porcentagem de Utilização (em TKU) dos Modais de Transportes no Brasil nos anos de 1995, 1997, 1999, 2004 e 2006.

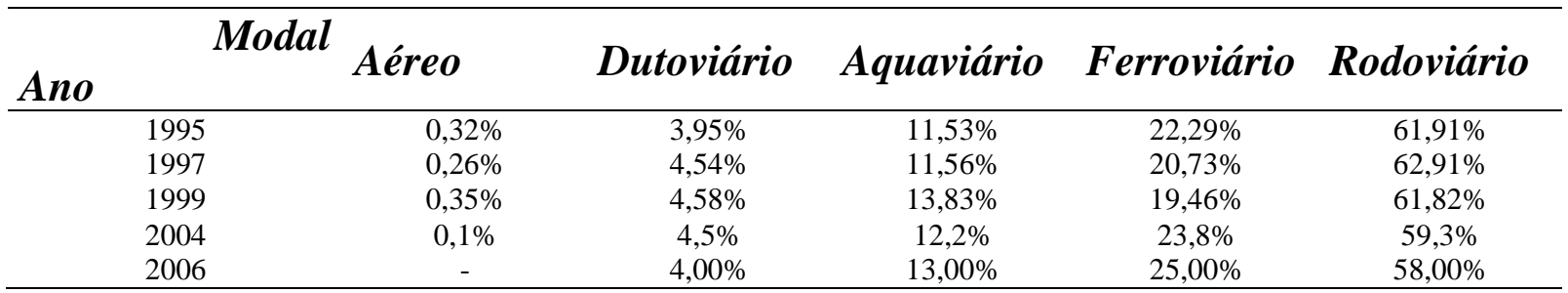

Fonte: [DAC, INFRAERO, GEIPOT, ANTT]

O Brasil é um exemplo de país que vem se adequando ao novo conceito de organização industrial e, cada vez mais, torna-se dependente da modalidade aérea do transporte. Os incentivos fiscais concedidos principalmente pelos governos estaduais, para atrair novos investimentos para seus estados, estimulam a descentralização das indústrias alterando e ampliando a tipologia da carga transportada via aérea, seja pela urgência de entrega, pela dificuldade de acesso a certas regiões, ou mesmo por questões de segurança (Pedrinha, 2000).

\subsection{Mercado Internacional}

Para complementar, o mercado de carga aérea no Brasil ainda é dominado pelas companhias estrangeiras, principalmente norte-americanas. E para completar, sabe-se que é impossível para nossas empresas, que entregam ao governo brasileiro $34 \%$ de suas receitas em forma de impostos, competir e ter algum sucesso sobre as companhias aéreas européias, que pagam uma média de $27 \%$ do seu faturamento em impostos, ou sobre as norte-americanas, que são taxadas em $7,5 \%$ de sua receita pelo seu governo.

No entanto, a participação da quantidade de cargas transportadas por via aérea no total de cargas movimentadas no País tem demonstrado um crescimento significativo, embora pequeno, como pode ser visto na Tabela abaixo. Por outro lado, sua participação no valor total transportado vem crescendo desde 1980, em decorrência de um aumento do emprego do avião para o transporte de cargas de alto valor agregado e produtos perecíveis. Em termos Globais, os fluxos dominantes de carga aérea estão concentrados em três mercados: Ásia-América do Norte, o Atlântico Norte (América - Europa), e Europa-Leste. 
Tabela 2.2: Evolução do Tráfego Aéreo Internacional Brasileiro entre 2000 e 2005.

\begin{tabular}{cccc}
\hline \multirow{2}{*}{$\boldsymbol{A N O S}$} & CORREIO & $\boldsymbol{C A R G A}$ & $\begin{array}{c}\text { TON-Km } \\
\text { Utilizados }\end{array}$ \\
\hline 2000 & T/km & T/km & 3.160 .688 .926 \\
$2000(\mathrm{r})$ & 15.150 .790 & 1.206 .160 .450 & 3.837 .736 .872 \\
2001 & 25.508 .737 & 1.482 .757 .433 & 3.597 .952 .156 \\
2002 & 24.914 .293 & 1.342 .191 .318 & 3.635 .922 .665 \\
2003 & 35.482 .752 & 1.406 .340 .946 & 3.706 .323 .118 \\
2004 & 44.829 .300 & 1.503 .540 .711 & 3.983 .828 .266 \\
2005 & 42.191 .301 & 1.652 .530 .089 & 4.191 .658 .723 \\
\hline
\end{tabular}

Obs.: A partir do ano de 2000 a metodologia para apuração do anuário foi revista.

Fonte: [Anuário do transporte Aéreo - 2005]

Um fator que tem influenciado a decisão das empresas aéreas na escolha da rota ideal diz respeito à prioridade de atendimento à demanda de passageiros. Esta prioridade gera, por parte das empresas aéreas e nos casos de vôos mistos de passageiros e cargas, mudanças nas rotas existentes, assim como a criação de novas rotas ou desativação de outras, ficando a carga a ser transportada, sujeita à oportunidade de espaço nas aeronaves. Isto só vem a demonstrar que o Brasil, assim como outros países, ainda tem seu transporte de carga aérea fortemente dependente aos vôos de passageiros.

\subsection{A Relação entre o Transporte de Carga e a Economia}

As crises econômicas influenciam negativamente o tráfego global de carga, enquanto o crescimento econômico promove o desenvolvimento do transporte aéreo. Contudo, a falta de uma política de desenvolvimento do país, a sobretaxação, o preço do querosene de aviação e a alta do dólar dificultam as empresas nacionais na concorrência com as internacionais.

O Produto Interno Bruto (PIB) mundial, é a melhor medida da atividade econômica global. A demanda por transporte, resultante da atividade econômica, cria grandes oportunidades para o crescimento da carga aérea, e por isso, verifica-se forte relação entre as variações do PIB mundial e a quantidade de carga aérea transportada, ao longo dos anos.

Ressalta-se, pois, o exposto na Figura a seguir: o decréscimo acentuado do PIB e da carga aérea mundiais, especialmente nos períodos de 1973 a 1975 e de 1978 a 1982, devido à crise dos combustíveis e, em 1991, época da Guerra do Golfo (Airbus, 1996). 
Figura 2.1: Crescimento de Carga Aérea x Atividade Econômica - Variação Anual (\%).

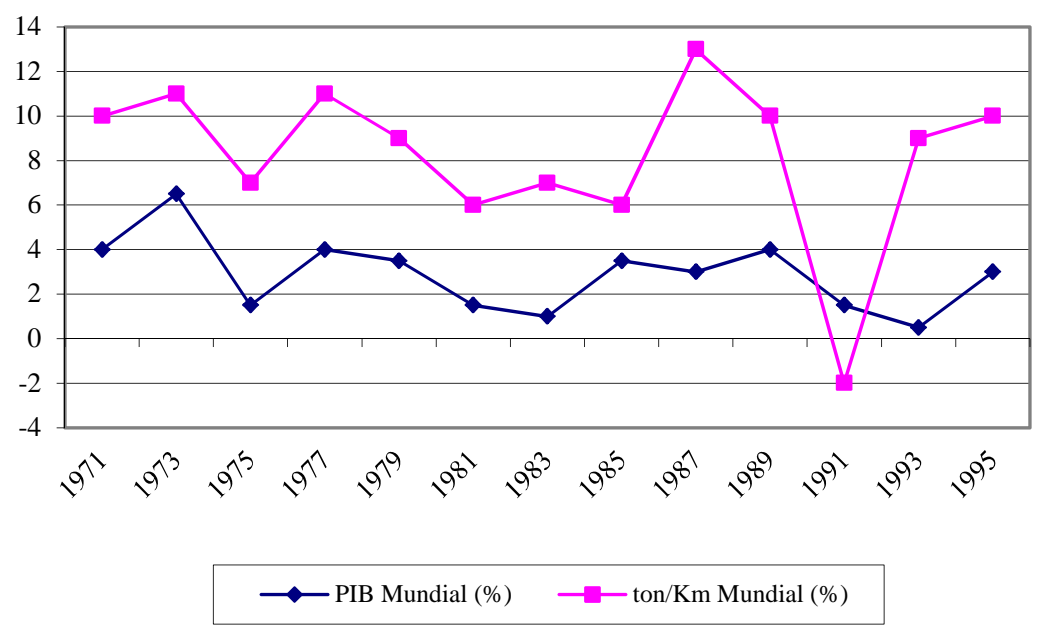

Fonte: World Air Cargo Forecast - Boeing - 1996/1997.

Segundo a BOEING (1996), o crescimento da carga aérea tende a ser mais alto em países emergentes, como o Brasil, onde procura-se minizar os custos de produção.

Tabela 2.3: Carga Aérea Transportada x PIB Anual Brasileiro entre 2000 e 2005.

\begin{tabular}{cccc}
\hline Anos & \multicolumn{2}{c}{$\begin{array}{c}\text { Carga Aérea Transportada }(\mathrm{t} / \mathrm{km}) \\
\text { Doméstico }+ \text { Internacional Pago } \\
\text { Correio }\end{array}$} & $\begin{array}{c}\text { Evolução do PIB Interno } \\
\text { Bilhões de US\$ }\end{array}$ \\
\hline 2000 & 71.542 .134 & 1.786 .378 .232 & 463,8 \\
Carga & 2.179 .661 .965 & 463,8 \\
$2000(\mathrm{r})$ & 98.084 .003 & 2.096 .522 .530 & 505,7 \\
2001 & 78.899 .580 & 2.148 .991 .530 & 459,4 \\
2002 & 81.657 .538 & 2.206 .467 .335 & 506,8 \\
2003 & 78.109 .676 & 2.449 .143 .233 & 604,0 \\
2005 & 123.664 .778 & 2.598 .607 .460 & 796,3 \\
\hline
\end{tabular}

Obs.: A partir do ano de 2000 a metodologia para apuração do anuário foi revista.

Fonte: Anuário do Transporte Aéreo - 2001 e IBGE

No caso brasileiro, fica demonstrado acima, através da comparação das evoluções anuais do PIB brasileiro e do movimento de carga aérea brasileira, a estreita relação entre o desenvolvimento da indústria e o mercado de carga. 


\subsection{Aeroportos}

A abertura da economia brasileira nos anos 90 promoveu o crescimento das importações, que praticamente ocuparam a capacidade dos principais terminais de cargas internacionais do País. Isso conduziu a pressões de capacidade nos principais aeroportos cargueiros (pela dificuldade de oferecer de imediato espaço para armazenagem), a execução de investimentos de ampliação de capacidade dos terminais de carga, a introdução de sistemas mais ágeis de liberação aduaneira de mercadorias pela Receita Federal e a implantação de Estações Adunaeira de Interior - EADIs.

No Brasil, apesar de contar com uma rede de 164 aeroportos operando no tráfego regular (ANAC), observa-se que o segmento de carga aérea apresenta uma acentuada concentração, em dez principais aeroportos, no que tange ao movimento de carga, sendo estes responsáveis por $87 \%$ do fluxo de carga do País. A INFRAERO é a responsável pela administração dos 66 principais aeroportos do país, incluindo os dez principais, onde são processados mais de 95\% do total de passageiros e carga transportados no Brasil.

Em relação ao tráfego internacional de carga, movimentado nestes dez principais aeroportos brasileiros, entre 1999 e 2005, observa-se na Figura 2.2, uma forte concentração em, basicamente, três aeroportos do sudeste do País: Internacional de São Paulo (SBGR), Internacional de Campinas (SBKP) e Internacional do Rio de Janeiro (SBGL).

igura 2.2: Movimento de Carga + Correio (Doméstico + Internacional) nos 10 Principais Aeroportos do País entre 1994 e 2006, por tonelada. 


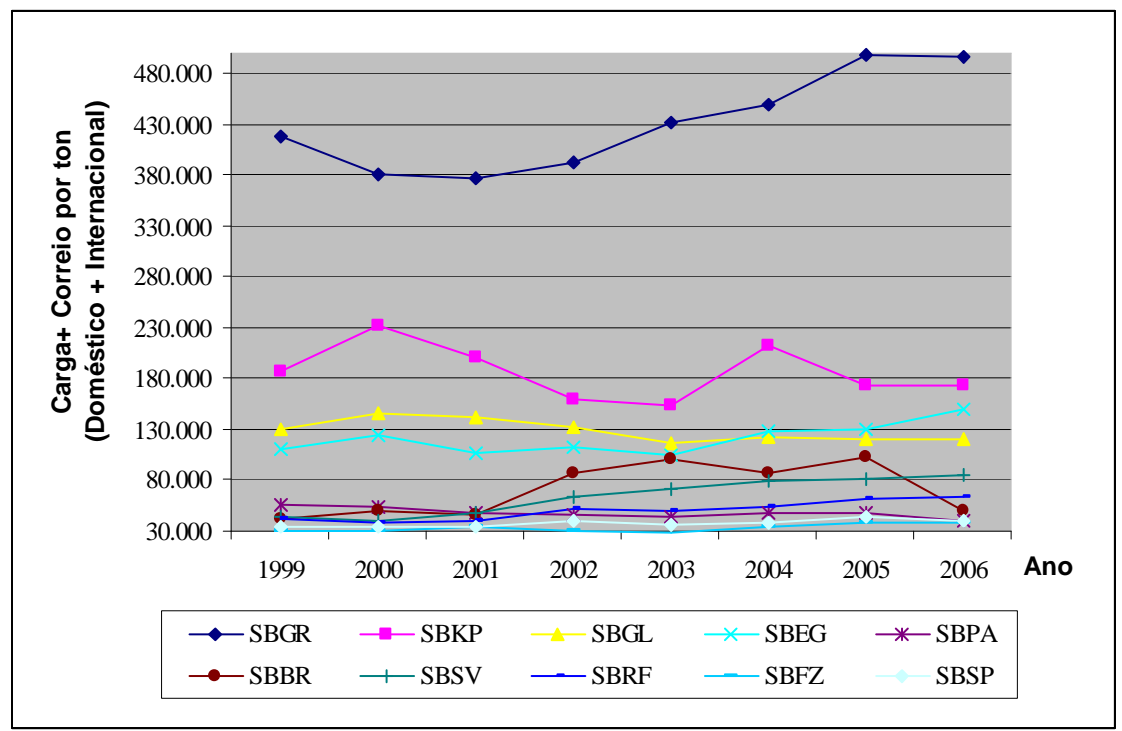

Fonte: [Movimento Operacional da Rede de Aeroportos da Infraero - 1979/2006]

Os clientes que adotarem o regime de aeroporto-indústria estarão minimizando os custos de manutenção de estoques, pela agilização da cadeia de abastecimento devido à redução do tempo de permanência das cargas no pipeline e do uso de "estoques sob consignação".

Para a INFRAERO fica a oportunidade de desenvolvimento de um novo nicho de mercado, incrementando as receitas do setor de cargas, especificamente as de armazenagem e capatazia, de preço específico (serviços logísticos) e de varejo aeroportuário (receita comercial). Acredita-se, no entanto, que além destes benefícios diretos que os aeroportos alvos do projeto do aeroporto-indústria terão, haverá ainda o impacto no crescimento do transporte aéreo, com aumento substancial do movimento de aeronaves.

Cabe ressaltar que, a intensa competição exigida no contexto mundial da globalização e da filosofia just-in-time significa que os operadores de carga aérea terão de competir não só na operação aérea em face ao menor tempo, mas também na eficiência nas operações de solo e nas soluções logísticas especializadas. Essa tendência a serviços diferenciados traz sensíveis reduções de tempo de aeronaves no solo, velocidade no giro das mercadorias e conseqüentemente, valor agregado aos clientes, que procuram por soluções personalizadas. 


\subsection{Centros de Distribuição}

Há muitos anos que os aeroportos não são mais tidos como meros terminais de troca de modos de transporte. Em um mundo globalizado, os aeroportos passaram a fazer parte de todos os elos da economia, quer seja como centro de distribuição entre economias ou como equipamento urbano provedor do espaço necessário para que estes negócios sejam desenvolvidos.

Assim como já acontecia nas EADIs, os aeroportos passaram a ser autorizados pela Receita Federal a armazenar, montar, beneficiar, recondicionar e embalar os produtos que movimentam. Esta medida, que também inclui redução de impostos, visa reduzir custos logísticos e agilizar a saída das mercadorias, favorecendo as exportações.

E ainda, para encontrar a máxima da velocidade, agilidade e credibilidade na entrega, os centros de distribuição/negócio estão sendo construídos próximos à ou em aeroportos que ofereçam uma vasta rede de vôos. Interligados a estes, existem ainda, centros de serviços oferecendo facilidades que agilizam os fluxos de perecíveis, centros de distribuição just-intime e de provisão de peças de emergência, e facilidades de logística reversa para reparos e finalização de produtos eletrônicos.

\section{Logística}

\subsection{Enfoques e Características}

Há alguns anos atrás, prevalecia na logística o transporte, o estoque e a armazenagem. Atualmente, porém, a ênfase vem sendo direcionada para a modelagem de problemas reais, levando-se em conta a integração de diversas funções logísticas como transporte, armazenamento, manutenção de estoques, processamento de pedidos, comunicação, produção, etc. A evolução nessa direção convencionou-se chamar Logística Integrada, tendendo, enfim, a conduzir a uma visão Sistêmica. Esta, passa a englobar os processos que envolvem toda a cadeia de suprimentos, desde a matéria-prima até a entrega do produto final aos clientes. Nesta fase, a logística adquiriu conteúdo estratégico e sua participação se faz necessária nas mais importantes tomadas de decisão empresariais. 
Contudo, cabe ressaltar que existem vários aspectos que se constituem em barreiras e limitações à evolução das empresas brasileiras na direção desta moderna Logística, tais como: a estrutura organizacional ineficaz e sem interação, entraves da legislação trabalhista, bases informacionais precárias, desestabilidades econômicas, concentração de esforços em funções puramente financeiras, telemática pouco desenvolvida, dificuldades de parcerias, sistemas de custo inadequados e finalmente, os sistemas de transportes que não atuam de forma integrada, o que permitiria a multimodalidade/intermodalidade e redução de seus custos elevados.

O entendimento do processo de escolha modal no transporte de carga é de grande importância para o planejamento e o gerenciamento da cadeia logística que envolve as mercadorias desde os locais de produção até os de consumo, porque permite estimar como os usuários podem mudar suas escolhas em resposta à mudanças nos atributos dos modos de transporte e, conseqüentemente, permite estimar a demanda por diferentes modos em diferentes situações. Neste âmbito, o uso de transporte intermodal/multimodal mostra-se como uma alternativa crucial para a execução eficaz e eficiente da cadeia logística.

No entanto, apesar de regulamentada, a operação intermodal ainda não é possível no Brasil, principalmente por falta de regulamentação sobre a forma de cobrança do ICMS, pois a mercadoria pode atravessar vários estados em diferentes modais, e cada translado, ao gerar a incidência de ICMS, faz com que os custos aumentem.

A adoção do multimodalismo tem por objetivo reduzir os custos logísticos que podem variar de $4 \%$ a $25 \%$ do faturamento bruto das empresas e com a sua aplicação, espera-se uma diminuição de $10 \%$ a $12 \%$ nos gastos totais com as exportações.

\section{2. Áreas Industriais}

Complexos industriais que enfatizam a logística just-in-time, como é o caso do AeroportoIndústria, a ser analisado mais profundamente no próximo ítem, devem ter ligação direta a múltiplas alternativas de acesso, incluindo locações ao longo das pistas de táxi do aeroporto. Os TECAs (terminais de carga aérea) serão responsáveis, também, pelo recebimento, conversão, classificação, armazenamento, despacho e documentação da carga. Outras facilidades de produção, processamento da carga e distribuição podem estar localizadas por todas as partes deste complexo, fornecendo o devido apoio para a logística industrial, tais 
como conteinerização, armazenagem de conteinerização, embalagem, paletização, despaletização, etc. Várias facilidades como empresas de carga aérea, serviços de aviação e manutenção de aeronaves, irão apoiar a operação, devendo existir, também, espaços setorizados para escritórios, de modo a separar pessoas de mercadorias (bens) em movimento.

Assim, é preciso entender que o conceito de plataformas logísticas nasceu na década de 60 na França, conseqüência do avanço dos estudos em gerenciamento de operações. Inicialmente com o objetivo de reduzir o fluxo de materiais distribuído de forma desordenada pelos terminais de carga da periferia das grandes cidades, as plataformas concentraram e otimizaram a distribuição, e, conseqüentemente, reduziram custos. Desta forma, um Aeroporto-indústria seria, então, um Zona de Atividade Logística (ZAL), justamente por estar em um centro de transporte com infra-estrutura intermodal relevante e deve ter características de gateway e hub.

Algumas providências devem ser tomadas pela permissionária, neste caso a INFRAERO, antes do início do funcionamento de um Aeroporto-Indústria, tais como: delimitação de área específica para armazenagem, definição das áreas onde serão construídas as instalações dos beneficiários (empresas) e realizadas as operações de industrialização, desenvolvimento de controle informatizado de entrada, movimentação, armazenamento, saída das mercadorias e requerimento de autorização para operar no regime de entreposto aduaneiro.

Com a perspectiva de desenvolvimento do aeroporto-indústria no sítio aeroportuário, todo o seu planejamento deverá ser revisto, levando-se em consideração o impacto do crescimento da demanda por transporte aéreo de carga e de passageiros.

\section{Aeroporto-Indústria}

O conceito de Aeroporto-Indústria é uma analogia ao projeto Global Transpark - Global Transpark, TransPark e GTP, cuja elaboração e desenho foram desenvolvidos por John Kasarda, Diretor do Instituto Kenan de Empresas Privadas da Universidade da Carolina do Norte, Estados Unidos. O primeiro Projeto Global Transpark está sendo desenvolvido em uma vasta área subutilizada de um aeroporto em Kinston, na Carolina do Norte, Estados Unidos e outros estão sendo analisados para a Tailândia e Filipinas. 
Este projeto irá contar expressamente com as instalações e com os procedimentos alfandegários para acelerar os processos de compras e exportação. Também terá tecnologia de informação intermodal e intercâmbio eletrônico de dados - EDI, que acelerará o manuseio e transferência dos materiais entre fábricas, aviões, trens e navios, fornecendo assim, acesso global rápido e outras vantagens competitivas às indústrias.

O conceito de aeroporto indústria é um entreposto aduaneiro de zona primária. As plantas industriais finalizam os produtos com o material recebido do exterior em conjunto com a produção local. Logo em seguida, estes produtos são exportados. Por exemplo, um computador produzido no North Carolina's Research Triangle Park será montado com componentes elétricos importados de Taiwan, disk drives de Singapore, circuitos integrados do Japão, microprocessadores da Coréia, teclado da Tailândia e tela do México. O objetivo é permitir que determinado estabelecimento de uma indústria importe, com reduçõa/suspensão de tributos, mercadorias e insumos e que, depois de submetidos à operação de industrialização, devem destinar-se ao mercado externo.

As zonas francas industriais são distritos industriais, onde empresas podem processar mercadorias importadas, com suspensão de impostos e sob supervisão aduaneira, desde que os produtos resultantes (que podem conter componentes nacionais) sejam destinados ao exterior. A maioria dos países permite a venda de uma parcela da produção no mercado doméstico, desde que pagando integralmente todos os impostos incidentes em uma importação normal.

Hoje, quando os insumos são trazidos para o Brasil, as companhias são obrigadas a pagar o Imposto de Importação e o Imposto sobre Produtos Industrializados (IPI) ou enquadrar-se no regime de draw-back. Além disso, há o custo do transporte desses produtos até a sede da empresa e de lá para o porto ou o aeroporto.

A INFRAERO, funcionará como uma espécie de "síndico" do aeroporto-indústria onde estará responsável pelo recebimento, controle físico e eletrônico e armazenamento da mercadoria importada. Embora a administradora tenha de abrir mão da receita de taxas, ela sairá ganhando com o projeto, por meio do aluguel das áreas, e outras receitas como armazenagem, concessões, varejo de apoio comefcial, etc. Quanto ao tamanho das unidades industriais, isto dependerá da necessidade de cada empresa. A INFRAERO vai disponibilizar as áreas e caberá as firmas a implantação da estrutura física das fábricas. 
Atualmente, o Brasil vem passando por um processo de desestatização de seus aeroportos, seja pela concessão de terminais, do sítio como um todo ou pela abertura de capital da Infraero. Assim, a implantação de aeroportos-indústria precisará também se adpatar segundo o modelo escolhido para cada aeroporto.

Os principais produtos a serem processados no Aeroporto-Indústria serão aqueles que contenham alto valor agregado, como montadoras de produtos aeronáuticos, indústrias químicas e de instrumentos de precisão, artigos de moda, produtos perecíveis (flores e frutos), eletroeletrônicos, medicamentos e fabricantes e lapidadores de jóias e gemas preciosas.

Após o conhecimento apresentado sobre a implantação de um Aeroporto-Indústria, cabe ressaltar que ainda há muito a fazer, principalmente no que diz respeito à burocracia, política e responsabilidade de operação do projeto. E este empreendimento ainda tem pela frente e à espera de definição os seguintes aspectos, a saber:

- A formulação de políticas públicas que possam apoiar o desenvolvimento e a operacionalidade destas plataformas logísticas no País;

- A criação de programas de marketing nacional e local que identifiquem e atraiam os parceiros potenciais;

- A identificação e a descrição de uma organização que deve ser criada para implementar e/ou operar os aeroportos-indústria;

- A elaboração de Planos Financeiros que descrevam as receitas e os custos, de acordo com o planejamento previsto em Planos Seqüenciais;

- A elaboração e/ou revisão de Planos Diretores destes aeroportos internacionais que possam nortear a apresentar as diretrizes da infraestrutura necessária; e

- A elaboração de estudos dos impactos ambientais decorrentes da implantação dos aeroportos-indústria.

Desta forma, pode-se definir como principal problema a ser resolvido ainda, a necessidade que os órgãos gestores do projeto "Aeroporto-Indústria” possuem de caracterizar a operação, a infraestrutura necessária e os parceiros possíveis. 


\section{O desafio logístico na implantação de um aeroporto-indústria no Brasil}

Companhias que não conseguem adotar as novas cadeias globais de fornecimento e responder com flexibilidade e rapidez a mercados em constante mutação estão perdendo terreno para aquelas que conseguem adaptar-se à nova realidade, onde as restrições e barreiras baseadas logísticas estão sendo transpostas (Greis et al, 1997).

No entanto, conforme mencionado anteriormente, sua implantação requer mudanças e adaptações de modo a viabilizar o Projeto. Não basta somente encontrar o sítio aeroportuário ocioso, elaborar uma Medida Provisória e fazer acordos com empresas. Um estudo mercadológico, por exemplo, é fundamental, uma vez que o equilíbrio entre a demanda e a capacidade é um requisito de sucesso e viabilidade. Quanto a operacionalidade da cadeia logística, esta costuma ser subestimada, causando prejuízos e perdas de eficiência inestimáveis, uma vez que deficiências verificadas e não corrigidas, numa economia globalizada, podem colocar uma empresa ou um país em situação de desvantagem comercial.

O gerenciamento desta cadeia logística é uma tarefa complexa que envolve alguns critérios essenciais ao seu desenvolvimento. Quando bem diagnosticados, estes critérios fornecem a informação necessária para se avaliar os componentes e conseqüentemente, identificar as possibilidades de melhoria no trinômio qualidade/produtividade/custos.

\subsection{Planejamento}

Com base nesse contexto, o projeto de Aeroporto-Indústria deve ter sua implantação muito bem planejada. Sua operacionalidade tem impactos tanto regionais como nacionais. A começar pelo aeroporto que deve ser internacional, tendo como função o escoamento da produção voltada à exportação. No entanto, a região também capta esta influência, mesmo que a população não seja consumidora, ela pode servir como produtora ou como mão-de-obra especializada. Além do mais, para viabilidade efetiva do projeto, esta região deve ter suporte de sistemas de transportes, telecomunicações e aparato comercial, que de preferência devem estar integrados aos outros sistemas respectivos das outras regiões de influência.

Na verdade, o empreendimento exige muita integração e desenvolvimento de diversos setores e isso só pode ser apurado com um planejamento prévio. Tendo em vista estas transformações 
em curso, deve-se estudar e entender bem o assunto, avaliar as possibilidades potenciais, reavaliar a cultura de operação para um novo processo comercial e romper com paradigmas.

\subsection{Implantação}

\subsubsection{Questão Aduaneira}

É precisamente crescente a exigência da velocidade de entrega e a possibilidade de reduzir o elevado tempo requerido pelos procedimentos aduaneiros que tornam o regime do AeroportoIndústria - caracterizado pela simplificação desses procedimentos - um elemento estratégico nessa cadeia logística de suprimentos.

As alfândegas brasileiras, que deveriam ser pontos de passagem, atuam como um verdadeiro gargalo no fluxo das mercadorias. Isto impõe ao transportador um adicional significativo no seu custo, por exemplo, de cerca de US\$ 150 a US\$ 200 por dia parado em fronteiras como as de Uruguaiana no Rio Grande do Sul, tornando-a menos competitiva.

Esse fenômeno de estrangulamento do tráfego, que também acontece na navegação fluvial, é observado não somente nas aduanas de fronteira, mas, também, nas barreiras fiscais entre os estados brasileiros e até mesmo dentro dos próprios estados, através das fiscalizações volantes. Assim, a criação de terminais alfandegados reduz a necessidade dessas paradas nas barreiras estaduais e nas aduanas de fronteira, otimizando o fluxo através do fator tempo.

\subsubsection{Questões Trabalhistas}

Outro fator a ser levado em consideração e que representa um limitante à viabilização do projeto, diz respeito à qualificação da mão-de-obra. O despreparo da mão-de-obra brasileira é fato notório e a velocidade da inserção tecnológica nos processos produtivos tem feito com que existam cada vez menos trabalhadores com qualificação para operar as novas tecnologias e atender a demanda das empresas, provocando custos mais elevados, reduzindo a produtividade e onerando as empresas que, são obrigadas a arcar com um ônus proveniente da estrutura social e muitas vezes, se vêm obrigadas a importar esta mão-de-obra necessária. 
Por outro lado, existe também a questão flexibilização da legislação trabalhista, viabilizando a livre negociação entre o capital e o trabalho, inclusive, através da possibilidade do livre trânsito de mão-de-obra entre os países, especialmente no âmbito do Mercosul.

Os países como os EUA, da União Européia, da Escandinávia, da Ásia, o Japão, o Chile, etc., promoveram a flexibilização do mercado de trabalho como forma de superar crises, evitar fugas de capitais e manter seus produtos e serviços competitivos num mercado globalizado, pelo simples fato da competição exigir agilidade e flexibilidade.

\subsection{Infraestrutura}

Ainda na fase de planejamento, devem ser elaboradas análises criteriosas quanto à identificação dos aeroportos com potencial para admitir em suas instalações o regime de entreposto aduaneiro. Como já mencionado anteriormente, para viabilizar a implantação do Aeroporto-Indústria, a infraestrutura aeroportuária deverá prover, dentre outros elementos:

- Um aeroporto internacional/internacionalizável com fluxo regular de importações e exportações;

- Capacidade do sistema de pistas para operações 24h por dia, frequiências, ligações;

- Capacidade do pátio para receber um maior número de aeronaves;

- Classificação de aeronaves para atendimento da demanda operação de aeronaves cargueiras, operação em acordo com as normas do Plano de Zoneamento de Ruído;

- Possuir área segregada para a instalação de plantas industriais;

- Complexo multimodal interligado que dê suporte à produção, distribuição e sistemas de transporte e apoio à transferência de carga com facilidades para conteinerização e distribuição;

- Facilidades para a carga aérea, empresas de carga aérea, serviços de aviação, manutenção de aeronaves, etc.;

- Acessibilidade, ligações com rodovias interestaduais, portos; 
- Sistema avançado de telecomunicações e tecnologia.

No caso brasileiro, os principais aeroportos internacionais, que são administrados pela INFRAERO, já possuem fluxo regular de importações e exportações, como Guarulhos-SP, Viracopos-SP e Galeão-RJ. No entanto, ainda há muito a fazer no que diz respeito ao Planejamento Aeroportuário e sua potencialidade, visto que o empreendimento exige espaço, setores de apoio e possibilidade de expansão. A questão acessibilidade e ligação com as outras modalidades de transporte ainda são assuntos que exigem estudos, principalmente a respeito da intermodalidade/multimodalidade.

As incertezas desta demanda (variabilidade, sazonalidade) aliadas a perecibilidade da capacidade (impossibilidade de estocar a capacidade para usá-la em momentos em que ela é inferior a demanda) caracterizam um problema continuamente enfrentado pelas empresas.

\subsection{Marketing}

O marketing é visto e entendido por muitos profissionais do ramo logístico como uma maneira de se fazer propaganda ou uma forma de atrair clientes. Marketing é muito mais do que marca e imagem, é uma ferramenta estratégica.

Há ainda um grande número de conflitos entre a área do marketing que estimula o lançamento de produtos diferenciados, e a área de produção, que prefere a padronização em grande volume. Uma forma de minimizar este impasse é a integração das três funções logísticas: Marketing, Produção e Transportes.

Com base nesse contexto, surgiu a idéia da distribuição de mercadorias pelo sistema de carga unitizada, com a utilização de pallets e contêiners do mesmo tipo. No entanto, no Japão os pallets medem 1100 x 1100 mm, padrão JIS. Na Europa, medesm 1200 x 800 mm, padrão denominado "Europallet". Os Estados Unidos possuem seu próprio padrão e o Brasil, as dimensões são 1200 x 1000 mm, padrão PBR. Ou seja, mesmo com a idéia de padronização por pallets já contamos com, no mínimo, quatro diferentes padrões.

Segundo Christopher (2001), é um erro presumir que o mundo está pronto para produtos padronizados. Ainda há diferenças consideráveis em relação a gostos, às preferências e às exigências locais. Quando há demanda por variedade no mercado, os produtos não devem ser 
configurados até que a demanda real seja conhecida. Em vez disso, devem ser produzidos em nível genérico, usando componentes ou materiais comuns, e mantidos como estoque em processo. A configuração final (montagem, acabamento e embalagem) deve ocorrer local ou centralmente, como prevê o projeto de um Aeroporto-Indústria.

\subsection{Sistemas de Transportes}

Com gastos equivalentes a 10\% do PIB, o transporte brasileiro possui uma dependência exagerada do modal rodoviário, o segundo mais caro, atrás apenas do aéreo. Enquanto no Brasil o transporte rodoviário é responsável por algo em torno de $60 \%$ da carga transportada (toneladas-km), na Austrália, EUA e China os números são 30\%, $28 \%$ e 19\%, respectivamente. Esse contexto brasileiro não é o mais propício para alteração de modal.

O Brasil encontra-se num processo de intensas transformações em relação ao papel do Estado no que tange à infraestrutura a aos serviços de transportes. $\mathrm{O}$ paradigma que se procura estabelecer está baseado numa transformação do modelo do estado empresário num modelo de Estado regulador-fiscalizador, com ênfase ao processo de desestatização e ao estabelecimento de parcerias entre a iniciativa pública e a privada.

O Governo é o poder concedente e responde pela formulação de políticas, desenvolvimento setorial, fiscalização e inspeção dos demais agentes no setor e, até recentemente, desempenhava com exclusividade, o papel de agente provedor da infraestrutura e/ou de serviços de transportes. O novo papel do governo está centrado no fomento dos investimentos privados e na coordenação, normalização e supervisão do setor de transportes.

No estágio atual, destacam-se, entre os gargalos institucionais deste setor, os seguintes:

- Convivência do setor com a atuação do Estado em todos os campos de atividades, tais como regulação, fiscalização, planejamento, investimentos e operação, situação que precisa ser adequada ao novo papel do Estado;

- Necessidade do estabelecimento de regras claras para a adequada criação de oportunidades de investimento privado; 


\subsection{Armazenagem}

Sistemas tradicionais baseados no estoque, que procuravam prever as necessidades do cliente por meio de previsões de vendas, foram desafiados pelo advento das soluções just-in-time, de reações rápidas, norteadas pela informação, e não pelo estoque, para atender as necessidades dos clientes. Substituir estoque por informações tornou-se o princípio diretivo dos gerentes de logística nas organizações que procuram obter respostas flexíveis e oportunas em mercados voláteis e com ciclo de vida curto (CHRISTOPHER, 2001).

Mas infelizmente, não é bem assim que este processo funciona em alguns países e aqui no Brasil. As cadeias de abastecimento convencionais não são transparentes em relação às informações relacionadas ao mercado e, inevitavelmente, mantêm estoques de reserva precavendo-se contra as incertezas da demanda. Como resultado, essas cadeias mantêm o estoque muito além do necessário, duplicando-o a cada interface comprador/fornecedor. Além da sobrecarga em termos de capital de giro, da falta de entrosamento e transparência, essas cadeias se tornam lentas em responder à demanda volátil, e pequenas mudanças na demanda do mercado final aumentam e distorcem à medida que se movem para trás na cadeia.

Para combater essas ineficiências na cadeia de abastecimento surge um novo estilo de relação entre os membros, com um compartilhamento mais aberto de informações. Ao invés de prever as condições, o objetivo agora é se tornar orientado pela demanda. Essa é a base do que veio a ser conhecido como logística de resposta rápida ou, como é conhecida no setor de varejo, resposta eficiente ao consumidor (ECR - efficient consumer response).

Essa é a base pela qual um Aeroporto-Indústria, que prioriza a simplificação e redução de custos, espera contar para ter sua implantação viabilizada. Ou seja, as informações são transmitidas e compartilhadas em tempo real, de forma que cada membro da cadeia possa planejar a produção, montagem, distribuição e outras atividades com uso eficiente de seus recursos e com diminuição de custos de estoque, armazenagem, embalagem e manuseio.

\subsection{Sistemas de Informação e Telemática}

Um importante ponto para a introdução da gestão logística é a gestão da cadeia de abastecimento, que compartilha informação, a fim de obter um sistema eficiente para reduzir custos desde suprimentos até as vendas. Mas, como essa cadeia movimenta mercadorias 
através de muitos setores industriais diferentes, desde o de matérias-primas até a entrega ao consumidor, a informação muitas vezes fica represada no caminho.

Nesse contexto, surgem os Sistemas de Informações que são compostos por elementos interrelacionados que coletam (entrada), manipulam e armazenam (processo), e disseminam (saída) os dados e as informações, fornecendo um mecanismo de retro-alimentação, ou seja, um feedback - conjunto de dados de saída utilizados para fazer ajustes ou modificações nas atividades de entrada ou de processamento do sistema.

O modelo de se fazer vendas ou negócios pela Web (ligações entre arquivos disponíveis na rede), substituindo os processos tradicionais por transações eletrônicas na internet, está cada vez mais presente no mercado corporativo como uma grande porta de comunicação entre empresas, proporcionando um mercado que visa integrar toda a cadeia logística, desde a indústria e distribuidores, até chegar ao consumidor final. Essas empresas em rede geram uma nova comunidade, um novo ambiente de trabalho, chamado de e-business, com serviços personalizados, de forma a integrar todos os parceiros da Supply Chain.

Segundo NOVAES (2001), o comércio eletrônico quando comparado com a forma de transação tradicional, apresenta inúmeras vantagens, a saber:

- Inserção instantânea no mercado globalizado;

- Relações mais ágeis entre consumidores e vendedores;

- Redução da assimetria informacional;

- Redução da burocracia e tempo, diminuindo-se erros e custos operacionais; e

- Análise mercadológica facilitada com o registro de informações e transações.

Esse é o ambiente que o Projeto de um Aeroporto-Indústria procura, com a possibilidade das empresas monitorarem em tempo real o seu produto, em todo o ciclo de distribuição, até os mesmos chegarem às mãos de seus clientes, onde inúmeras possibilidades de serviços adicionais são sugeridas por conta do cenário atual, o que poderá ser traduzido em vantagens competitivas se as empresas souberem explorar adequadamente estas soluções. 
Segundo Paulo Fernando Fleury, professor do CEL - Centro de Estudos em Logística da Coppead /UFRJ, a experiência têm demonstrado que diferentemente do que se possa imaginar, o maior gargalo do e-business não se encontra na atividade física porta a porta, mas sim na atividade de fulfillment, ou atendimento do pedido, que compreende o processamento do pedido, a gestão do estoque, a coordenação com os fornecedores, e a separação e embalagem de mercadorias.

\subsection{Nível de Serviço}

O serviço ao cliente é um conceito amplo, difícil de ser definido em uma única frase. Ele abrange todos os pontos de contato entre um fornecedor e um comprador, incluindo os elementos tangíveis e intangíveis. O desempenho da logística é fundamental para se alcançar a satisfação do cliente e do modelo de encadeamento serviço-relacionamento-retenção.

De forma simplificada, a idéia é atender e, de preferência, superar as expectativas do cliente, direcionando os processos logísticos de maneira a cumprir as metas de serviço. Muitas empresas, incluindo os países em desenvolvimento, estando aí o Brasil, supõem que entendem seus clientes, mas na verdade não conhecem nem o perfil deles. Isso quer dizer que, em vez de oferecer pacotes de serviços iguais para todos os clientes, a organização flexível deveria buscar diferenciar o pacote para atender às exigências de cada cliente de forma personalizada.

\subsection{Custos: Vantagem Comparativa}

No Brasil, a abertura econômica de 1994 trouxe exigências logísticas imediatas, implicando em distribuição e suprimento mais fracionados (just-in-time, ECR, etc). Isso levou, primeiramente, a custos logísticos mais elevados (NOVAES, 2001). Agora é hora de reduzilos e para isso, é preciso ter conhecimento de todo o processo e não somente do custo final.

De acordo com a ABLM - Associação Brasileira de Movimentação e Logística, estima-se que o custo logístico de uma empresa pode equivaler a $19 \%$ do seu faturamento. O crescimento desse setor faz com que o número de operadores logísticos no País aumente na razão de aproximadamente 5\% ao mês. Como consequiência dessa expansão, surgem empresas de transporte que se intitulam operadores logísticos, oferecendo serviços ineficientes e a preços baixos. Definitivamente, logística não se restringe a armazenar e distribuir produtos. 
O próprio conceito de Logística Integrada engloba desde a previsão de vendas, estoque/inventário, embalagem, fluxo de informação, movimentação, aspectos legais, planejamento operacional, armazenagem e serviço ao cliente até suprimentos, transporte e planejamento estratégico. Definir o custo de cada uma dessas etapas é o grande desafio das empresas que estejam buscando aperfeiçoar a gestão de suas cadeias de abastecimento, aumentar sua produtividade e penetrar nos novos mercados internacionais.

Segundo NOVAES (2001), nos Estados Unidos os custos de transportes representam 59\% dos custos logísticos, seguidos pelos custos gerais de juros, impostos, obsolescência, depreciação, seguros, com $28 \%$, e por outros custos de armazenagem, despacho e administração, de $13 \%$. No Brasil, não existem estatísticas precisas e muitas das entidades do ramo divergem em seus valores. O projeto de um Aeroporto-Indústria pretende otimizar estes valores, uma vez que prevê incentivos por parte do Governo em reduções de impostos e também, valores inferiores nas questões seguro, obsolescência, armazenagem e administração.

O transporte, com sua característica de não poder ser armazenado, uma vez que os assentos ou toneladas/quilômetros oferecidos e não-utilizados não podem ser estocados para o futuro, é intermediário no sistema econômico. Ou seja, a atividade econômica necessita dos transportes, que funcionam como um eixo entre a produção e o consumo, como elo do processo produtivo. Os meios de transporte ampliam os mercados propiciando economia de escala. Cada etapa nos dá o preço básico mais o custo de transporte e, por conseqüência, a cada etapa seguinte, um novo custo de transporte é adicionado.

Já o custo financeiro, é um dos que mais sobrecarregam o total da logística, por que está ligado à taxa de juros, que, mesmo tendo baixado, continua muito mais alta que na Europa e nos EUA. Calcular, por exemplo, o custo do ICMS que incide sempre que se movimenta o produto na cadeia é complexo, porque ele incide em cascata.

Como já mencionado anteriormente, o importante para a empresa no conhecimento de suas estatísticas incide não só em saber sua participação na Economia, mas principalmente em avaliar os custos dos elementos básicos (etapas e processos), o que motivará novas medidas de planejamento, regulação e incentivos por parte dos órgãos. 


\section{Conclusões}

A principal mensagem deste trabalho é chamar a atenção para a nova filosofia da cadeia logística onde não se analisa mais somente a produção, o transporte e a distribuição e sim a relação destes três elementos com a competitividade, a redução de custos e tempo e as novas tecnologias já existentes. Sendo assim, foram abordadas apenas as questões relativas à esta nova filosofia da logística, sua importância e suas limitações, no caso brasileiro, à viabilização do projeto de um Aeroporto-Indústria.

Para sua implantação, toda uma maneira nova de pensar e gerenciar se faz necessária; todo um conhecimento sobre o transporte de cargas, mercados, logística, infraestrutura, sistemas de informação, processos burocráticos, legislação e economia é vital, uma vez que para sua operacionalidade ter sucesso são necessários investimentos por todos os envolvidos. Desta forma, o presente trabalho identificou como gargalos e limitantes do sistema logístico à implantação do Projeto Aeroporto-Indústria no Brasil, os seguintes:

- O processo de crises e as mudanças presentes na economia brasileira, decorrentes dos efeitos da globalização nos campos econômicos e financeiros;

- Falta de um planejamento prévio, político nacional, estratégico e orçamentário que tenha uma visão sistêmica do setor de transporte e da economia brasileira;

- Entraves burocráticos e da legislação inadequada para a implementação de uma rede multimodal integrada;

- Falta de uma ampla e irrestrita reforma tributária;

- Gargalos alfandegários, uma vez que as alfândegas brasileiras que deveriam ser pontos de passagem atuam como um verdadeiro impasse no fluxo das mercadorias;

- Desqualificação profissional;

- Falta de um estudo mercadológico que identifique aeroportos, demanda (variabilidade, sazonalidade) e perspectivas do mercado; 
- Estoques independentes a cada fase da cadeia, que segundo Christopher (2001), agem como reservas que distorcem e ampliam os requisitos de demanda;

- Falta de um compartilhamento mais aberto de informação que vise combater ineficiências na cadeia de abastecimento;

- Ineficiência na atividade de fulfillment, ou atendimento do pedido;

- Falta de conhecimento dos custos totais.

O presente trabalho não pretende encerrar as discussões sobre as limitações logísticas à viabilização de um Aeroporto-Indústria ou questões relativas à logistica da carga aérea. Sendo assim, sugere-se como continuidade/complementação deste trabalho os seguintes estudos:

- Analisar uma nova metodologia de escolha de sítio aeroportuário para o específico empreendimento em questão com um estudo de viabilidade e impacto econômico;

- Diagnosticar, de forma aprofundada, os possíveis parceiros ao Projeto;

- Estudo aprofundado dos sistemas de transportes e sua respectiva interação com o transporte de carga aérea com vias à exportação;

\section{Referências}

AIRBUS Industry, (2000) Global Market Forecast 2000-2019.

BREWER, A.M., BUTTON, K.J., HENSHER, D.A., (2001) Handbook of Logistics and Supply-Chain Management, $1^{a}$ Edição, Pergamon - Elsevier Science, Kidlington, Oxford, UK.

BURMAN, P.K., (1999) Uma análise de crescimento do Segmento de Carga Aérea Doméstica no Brasil. Tese de M.Sc., COPPE/UFRJ, Rio de Janeiro, RJ, Brasil.

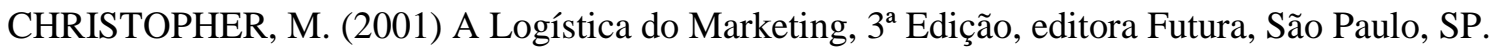

COMANDO DA AERONÁUTICA (1999) Departamento de Aviação Civil - DAC. Instituto de Aviação Civil - IAC. Demanda detalhada dos aeroportos brasileiros. Rio de Janeiro.

COMANDO DA AERONÁUTICA (1999) Departamento de Aviação Civil - DAC. Anuário do Transporte Aéreo - 1980 - 1997. V. 1: Dados Estatísticos. 
DUARTE, P. C., (1999) Modelo para o desenvolvimento de Plataforma Logística em um Terminal: Um estudo de caso na Estação Aduaneira do Interior - Itajaí/SC. Tese de M. Sc. Programa de Pós-Graduação em Engenharia de Produção/UFSC, Florianópolis, SC, Brasil.

GEIPOT, Ministério dos Transportes, (1997) - Estudo do Corredor de Transporte Rio de Janeiro - São Paulo - Campinas. Rio de Janeiro.

GREIS, N. P., KASARDA, J. D. e POWELL, W. T. (1997) Center for Logistics and Global Strategy: How the Global Transpark Will Support The Agile Enterprise. Kenan Institute of Private Enterprise.

GUIA DE CARGA AÉREA, Revista, (2002) Mercado - Balanço Completo Deste Setor. Aviação em Revista Editora Ltda., Ano 4, No 4.

INFRAERO, (2006) Site visitado ao longo do segundo semestre de 2006. www.infraero.gov.br.

JoCWEEK, The Journal of Commerce, The NewsMagazine of Trade Logistics, Aer.o.trop.o.lis, A cluster of logistics-related facilities around an air-cargo hub, used by shippers for just-in-time response. July 9-15, 2001 Volume 2, Issue N0. 27.

KASARDA, J.D..Global Transpark Brasil - Infraestrutura para uma Vantagem Competitiva. Revista Tecnologística, ano III, N0 24, Nov./1997, pp.26-31.

NOVAES, A.G. (2001) Logística e Gerenciamento da Cadeia de Distribuição - Estratégia, Operação e Avaliação, editora Campus, Rio de Janeiro.

PANORAMA SETORIAL. (1997) Transporte de Cargas no Mercosul, Mar. Gazeta Mercantil.

PEDRINHA, A. J., (2000) Carga Aérea no Brasil: Características Gerais do Mercado e Fatores Influentes. Tese de M. Sc. COPPE/UFRJ, Rio de Janeiro, RJ, Brasil.

TORRES, R. R., MATERA, R. W., ESPÍRITO SANTO JR, R. A. (2003) The Air Cargo Market in Brazil: Challenges, opportunities and Perspectives. In: 7th Conference of the Air Transport Research Society (ATRS), Toulouse, France. 